\title{
Herd Immunity in India: A Review
}

\author{
Sheema Fatima Khan
}

\section{ABSTRACT}

\begin{abstract}
Herd Immunity is a brilliant solution to tackle and control global pandemics, if taken proper route for immunization such as through vaccination. It is defined as the number of immune individuals against a transmissible virus in a completely susceptible population. The term herd protection or herd effect is the protection to the whole population due to herd immunity. Herd immunity threshold is the minimum proportion of immune population required for herd effect or herd protection. To calculate the threshold, we use basic reproduction number $\left(\mathbf{R}_{0}\right)$ to measure the rate of transmission of pathogen, in this case SARS-CoV-2. However, a better measure is effective reproduction number $\left(R_{\mathrm{e}}\right)$. India is major example of herd immunity. Despite strict lockdown and other Covid measure, due to already crowded area the virus could spread fast and to vast majority of people if one of them were to catch it. This explains the steady decline in the number of coronavirus cases in India. At the end, until an approved effective vaccination available, public will still need to follow all the CDC guidelines in order to avoid the large deaths along with natural infection.
\end{abstract}

Keywords: SARS-CoV-2, Herd immunity, Herd effect, Basic reproduction number, herd immunity threshold, pandemic, vaccinations.
Published Online: January 19, 2021

ISSN: 2593-8339

DOI: $10.24018 /$ ejmed.2021.3.1.671

\section{Sheema Fatima Khan*}

Shadan Institute of Medical Sciences, Teaching Hospital and Research Center, India.

(e-mail: sheemafatimak@gmail.com)

*Corresponding Author

\section{INTRODUCTION}

Herd immunity is a concept that has been embraced in the past for several decades to control various epidemics. In the present times, the diseases which had earlier caused deadly pandemics, are now virtually eradicated, for e.g., Bubonic Plague pandemic in $14^{\text {th }}$ century also called Black Death. Smallpox is also considered to be eradicated. Others are well under controlled and almost on verge of eradication like the Polio virus and Measles.

In this day and age, the novel Coronavirus pandemic has again highlighted the necessity of herd immunity. Due to increase in literacy rate around the globe, most people are now aware of the term herd immunity and are taking steps to achieve it. This global catastrophe caused by tiny, microscopic organism requires the efforts of all individuals on earth to overcome these distressing times and bring back our live on tract to the new normal.

This review aims to provide an easy understanding of what herd immunity is, its importance and also highlights its significant role in declining curve of nCovid-19 cases seen in the populous country, India.

\section{WHAT IS HERD IMMUNITY AND HERD EFFECT?}

Herd immunity is an idea that states, for a particular disease with ability to create a pandemic to come to an end, especially those caused by microbes which depends on person to person transmission for its survival, most and not all the population in the community has to be immunized. The immunized individuals then can act as barrier for spread which is known as herd effect or herd protection. Therefore, the ones who are not immunized are susceptible to disease, but they cannot pass it on to large number of people as they are immunized. After attaining certain level of immunization for a particular period of time, which may take years, the virus can be completely eradicated due to limitation of transmission with decreases its survival in that community [2], [3].

\section{A. How Do We Achieve It?}

We can achieve herd immunity by either vaccination or directly coming into contact with the virus.

1. If the virus naturally infects large number of people, then those which did survive the disease are now immune and can act as a barrier for further transmission. But this method is also associated with higher death rates and after disease complication, at present called a long COVID haulers.

2. Vaccination can introduce the important component of the virus into human body and lead to same immunogenic response. This is a relatively safe method as the immune response is not fatal and also reduces the high mortality associated with getting the real disease [2].

\section{B. Herd Immunity Threshold}

herd protection or herd effect is only seen when certain level of individuals in the given susceptible population has been immunized. This essential characteristic level of coverage is known as the herd protection threshold (HPT). The level of immune individuals in the population must be higher than the threshold to effectively control the spread of disease [8]. 


\section{REPRODUCTIVE RATE OF INFECTION $\left(\mathrm{R}_{0}\right)$}

The basic reproduction number $\left(R_{0}\right)$ is a mathematical term used to measure the rate of transmission or spread of a disease [4], [6]. It is defined as the average number of secondary infections caused by one primary infection during their infective period in a completely susceptible population [5], [7]. It denotes to how many individuals in susceptible population can be infected with the disease by singe infected person [8].

\section{A. The Reproduction Factor Depends on the Following} [6]

1) Mode of transmission: It can be via air droplets, fomite and body fluids exchange through sexual interaction, intravenous drug infection, using non-sterilized needles or other piercing objects in medical care.

2) Duration of infection: The longer the period of infection, more the chances of spreading disease.

3) Contact rate-how many susceptible does the infected individual meets increase the rate of transmission.

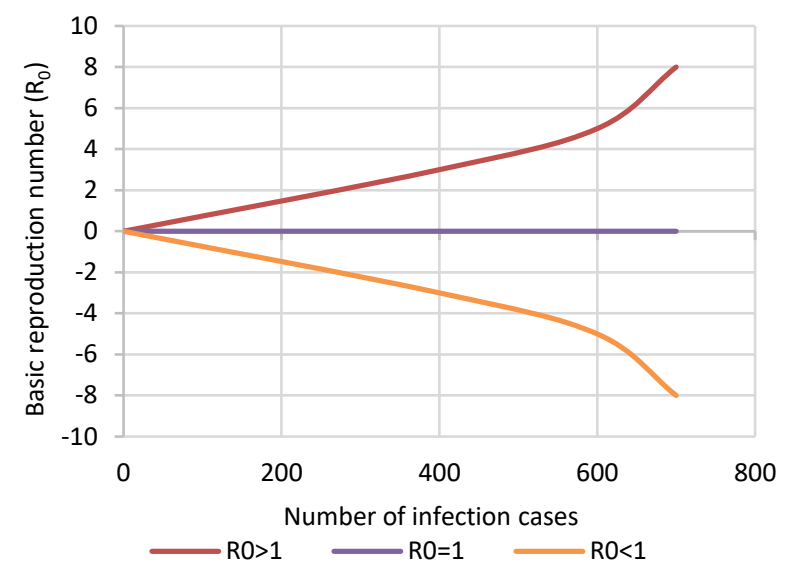

Fig. 1. Basic reproduction number $\left(\mathrm{R}_{0}\right)$ vs infection.

The above graph shows the relation between the rate of infection or basic reproduction number versus the number of infective cases.

This includes three cases:

1. If $\mathbf{R}_{\mathbf{0}}>\mathbf{1}$; indicates the rate of transmission is high and the number of infective cases is more than non-infected or recovered cases. Thus, such diseases have the potential of causing pandemics.

2. If $\mathbf{R}_{\mathbf{0}}=\mathbf{1}$; Stabilizes the infection curve. The infected person can only spread to one other susceptible person.

3. If $\mathbf{R}_{\mathbf{0}}<\mathbf{1}$; The disease dies out as a value less than one indicates the disease cannot be to even one individual or have very low transmission rate. For an infection to persist, each infected individual must, on average, transmit that infection to at least one other individual [6], [10].

The following graph below shows herd immunity threshold by disease. On X -axis basic reproduction number also called reproductive rate of infection is plotted with 1 unit $=2$ reproduction number. On y axis the percentage of people around the world required to get immunized is plotted. The meeting point of these two is the herd immunity threshold for that disease.

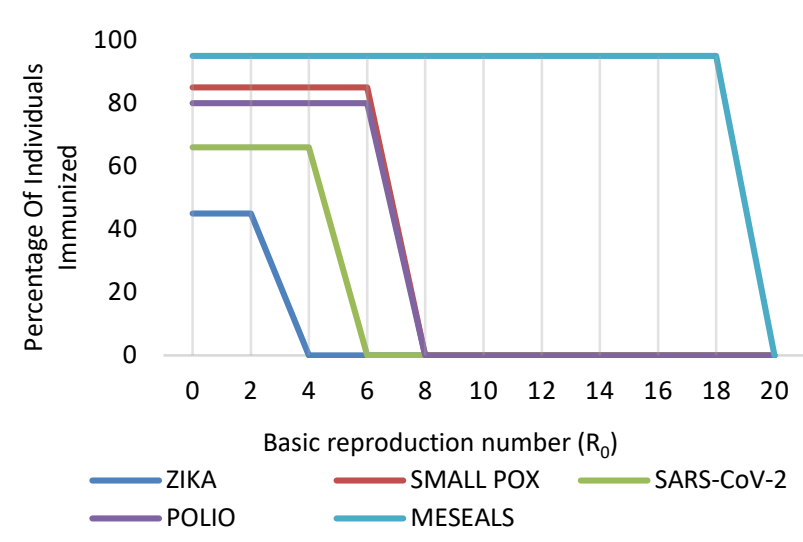

Fig. 2. Herd immunity threshold by disease.

\section{B. Calculating the Percentage of Immunization Coverage of Coronavirus Using $R_{0}$}

The herd immunity threshold (HIT) for a disease is given by the formula:

$$
H I T=1-(1 / R O)
$$

Thus, for SARS-CoV-2, $\mathrm{R}_{0}$ is in the range of 2-3.

Suppose we take the value of $\mathrm{R}_{0}=2.5$, then the HIT would be:

$$
\begin{gathered}
H I T=1-(1 / 2.5)=0.60 . \\
H I T \%=0.60 \times 100=60 \%
\end{gathered}
$$

In other words, assuming no measures to limit the spread, $60 \%$ of the population will need to be infected before we can expect the new infections to start decreasing [17].

The average Reproductive rate of infection $\left(\mathrm{R}_{0}\right)$ of coronavirus is around 2-3 depending on the means of transmission with includes contact with contaminated surfaces such a handshake with infected person or contaminated objects or through the infected air droplets. If we calculate the percentage of people to be immunized in Indian population of about 1.4 billion, then $60 \%$ of 1.4 billion is equal to 840 million people. Therefore, 840 million people need to be immunized and more than threshold to prevent the virus from spreading.

Once this threshold is achieved then the if the virus infects the remaining of the population non-immunized individuals cannot spread further as rest of population is immune against it. This limits the spread of such microorganism and reduces the chances of its survival which are solely dependent on transmission. At certain point of time if the same level of immunization is maintained above the herd immunity threshold then the virus disappears over time and the disease can be eradicated completely. Some of the great examples of eradicating diseases using this method are Bubonic plague which caused the black death pandemic in Europe transmitted by zoonotic bacteria Yersinia pestis and viral disease Smallpox caused by variola virus [19], [20]. 
TABLE 1: $\mathrm{R}_{0}$ VALUE OF VARIOUS DISEASE ACCORDING TO ITS MODE OF TRANSMISSION ALONG WITH ITS CALCULATED HERD IMMUNITY THRESHOLD [8]-[11]

\begin{tabular}{cccc}
\hline Name of Disease & Mode of Transmission & $\mathrm{R}_{0}$ Value & $\begin{array}{c}\text { Herd } \\
\text { Immunity } \\
\text { Threshold (\%) }\end{array}$ \\
\hline Influenza & Respiratory droplets & $0.9-1.6$ & $50-65$ \\
Swine flu (H1N1) & Respiratory droplets & $1.4-1.6$ & $50-65$ \\
1918 Spanish flu & Respiratory droplets & $1.4-2.8$ & $55-75$ \\
Ebola & body fluids & 2 & $70-80$ \\
Smallpox & Respiratory droplets & $3.5-6$ & $80-85$ \\
Zika virus & body fluids and & $0.5-3$ & $40-65$ \\
Polio & Respiratory droplets & respectively & $80-85$ \\
Measels & Respiratory droplets & $4-6$ & $80-95[9]$ \\
SARS-CoV-2 & Air born & $12-18$ & $60-65$ \\
\hline
\end{tabular}

\section{Limitation of Basic Reproduction Number $R_{0}$}

It is challenging to get accurate and precise aggregate of individuals infected during pandemic considering the various factors such as lack of infrastructure and financial support or lack of coordination and cooperation from different local cluster regions that may get in the way of testing, tracing and isolation strategies and keep record of such infections. Therefore, to measure basic reproduction number $\left(\mathrm{R}_{0}\right)$ in the course of pandemic does not provide an authentic value. Consequently, it is estimated retrospectively from seroepidemiologic data [12].

\section{Effective Reproductive Number $R_{e}$ or $R_{t}$}

To overcome the above challenge effective reproductive number denoted by $R_{e}$ or $R_{t}$ is used. It is defined as the average number of secondary infections caused by a single primary infected individual at time $t$ in the partially susceptible population. It is calculated by multiplying $\mathrm{R}_{0}$, with the fraction of susceptible individual of the population denoted by ' $\mathrm{S}$ '.

$$
\mathrm{R}_{\mathrm{e}}=\mathrm{R}_{0} \times \mathrm{S}
$$

If the immunity of the population increases through vaccination or recovery after the infection, then the fraction of susceptible individual decreases which decreases the $\mathrm{R}_{\mathrm{e}}$ value. When $R_{e}<1$, it indicated that the population has reached or nearing to the herd immunity threshold and further increases beyond the threshold over a period of time would eradicate the disease completely. [14] One of the major significances of $R_{e}$ is to monitor the impact of a vaccination program towards herd immunity $R_{t}[13]$.

\section{INDIA}

India has a population of 1.4 billion on 2.8 million sq. $\mathrm{m}$ surface area. India identified its first case of COVID-19 in a student who came back from Wuhan, China, on January 30, 2020. India imposed its nationwide lockdown with only 500 cases reported at that time [21]. What is contrasting about this country is that even with large population with poor health care infrastructure and crowded areas India reports one of the lowest mortalities and even the cases during initial few months of pandemic. There was a spike of cases in September with over 90,000 cases reporting but it gradually reduced in coming 2 months and as of January 2021 below 20,000 per day is reported. This could be due to:

1. Infrastructural
India restricted its international travel only on March 21, 2020 whereas China, its geographical neighbor had reported mysterious pneumonia like condition (covid-19) back in November 2019. Therefore, there must have been exposure and even high spread of virus before it was tested and identified [22].

One of key factors that these symptoms were not reported during the pre-lockdown period was because of the fact that India is out of 1683 disease outbreaks in India $71 \%$ were due to viral pathogens. This was reported by the Integrated Disease Surveillance Program (IDSP) of the Ministry of Health and Family Welfare (MoHFW) of the government of India in the year 2017. Thus, even when Indian were infected with nCovid-19 many would not have turned up to clinics and resort to home remedies dismissing it as the so called usual viral fever. The health care workers too could have same mentality at that time [26].

Lack of testing strategy is also one highly likely possibility of fewer cases reported which may be due to the above stated reason or due to lack of and resources and finance.

\section{Environmental}

Another important factor is the age of Indian population majorly comprises of individual under the age of 35 years and less [16]. As most researches proves this range of age mostly experience mild to asymptomatic symptoms with death rate quite low to about 0 to $0.1 \%$ [16].

According to the Köppen classification of climatic zones of the world, India has either a dry (type B) or tropical climate (type A) [23]. Due to high temperatures and high relative humidity levels may have contributed significantly reduce SARS-CoV-2 transmission [24], [22].

\section{Molecular}

The cross immunity due to infection by other human coronavirus producing cross-reactive antibodies generated may also have a protective role in reducing deaths and severe symptoms in population affected by COVID-19. Such cross immunity could have been a result of transmission of coronavirus from animals due to possible antigenic similarities among human and animal corona viruses [22] which usually does not occur but considering India's large poultry farms and meat shops including handling of such products with bare hands and lack of hygienic and sanitized conditions it may have taken place.

The polymorphism of ACE2 protein coded by a gene on the $\mathrm{X}$-chromosome may have been undergone mutation and expressed a unique structure of the ACE2 receptor in the Indian population that may have reduced its transmissibility and severity. The ACE2 receptor is found on lungs and GI tract and is responsible for interaction with spike protein of SARS-CoV-2 [25]. Yet, this still does not have much importance and still under consideration.

Therefore, considering the time period of pandemic and all the above factors it would imply that a large significant amount of the population who have survived the disease must have achieved of immunity against the virus. There can then high chance of Indian population reaching their herd immunity threshold, or at least in some of the rural Indian communities as localized herd immunity.

One of the best examples of such localized herd immunity in India is the Dharvi Slum in Mumbai, known for being the 
largest slum in the world. It has been plagued by the pandemic in the early April of year 2020. Due to stringent and rapid action, the virus was brought under control. But due to crowded condition such as $8-10$ person living per houses, plus the narrow spaces between each house have contributed to a larger spread in the community in a short span of time. Subsequently, a study by The Tata Institute of Fundamental Research in July have demonstrated that around $57 \%$ of the individuals have been tested positive with nCovid-19 antibodies or SARS-CoV-2 antibodies [15]. This is almost equal to herd immunity threshold of COVID19.

This can also become a reason why the new SARS-CoV2 variant, known as VUI-202012/01 (the first "Variant Under Investigation" in December 2020) first reported by UK which is said to be $70 \%$ more transmissible [18] is not causing any incline of curve of infectious cases in the country.

\section{CONCLUSION}

Herd immunity is a very intriguing and optimistic idea to overcome any pandemic. It teaches us that no matter what the circumstance are there is always a way-out. With the development of vaccines, it has opened the door to achieve the targeted herd immunity threshold in a safe and secure process. India, taking into account the various interplay of its complex feature of huge population has shown remarkable resistance to the new coronavirus. Despite the enthusiasm to achieve herd immunity, until an approved vaccine is available for distribution, we still have to follow testing, tracing, isolation and social distancing strategies to control the spread of coronavirus. It would be irrational, in this era and age of advancing innovation and technology, to go for herd immunity naturally by getting infected with the virus as it may lead to far too many deaths and severe after disease complication especially see in the weaker and vulnerable sections across our planet.

\section{ACKNOWLEDGEMENT}

I would like to acknowledge Dr Nusrat Aziz and Fazal Mustafa Ali Khan for providing valuable resource and guidance.

\section{REFERENCES}

[1] Glatter K, Finkelman P. History of the Plague: An Ancient Pandemic for the Age of Covid-19. The American Journal of Medicine. 2020 Sep 24.

[2] D'Souza G, Dowdy D. What is Herd Immunity and How Can We Achieve It With COVID-19? [Internet]. Johns Hopkins Bloomberg School of Public Health. 2020 [cited 5 January 2021]. Available from: https://www.jhsph.edu/covid-19/articles/achieving-herd-immunitywith-covid19.html.

[3] John T, Samuel R. Herd immunity and herd effect: new insights and definitions. European Journal of Epidemiology. 2000;16(7):601-606.

[4] Rothman K, Lash T, Greenland S. Modern Epidemiology. 3rd ed. Lippincott Williams \& Wilkins (LWW); 2020.

[5] Dietz K. The estimation of the basic reproduction number for infectious diseases. Statistical methods in medical research. 1993 Mar;2(1):23-41.

[6] Ramirez VB, Biggers A. What is R0? Gauging contagious infections. Healthline. 2020 Apr.

[7] Guerra FM, Bolotin S, Lim G, Heffernan J, Deeks SL, Li Y, Crowcroft NS. The basic reproduction number (R0) of measles: a systematic review. The Lancet Infectious Diseases. 2017 Dec 1;17(12): e420-8.

[8] Scarbrough Lefebvre C, Terlinden A, Standaert B. Dissecting the indirect effects caused by vaccines into the basic elements. Human Vaccines \& Immunotherapeutics. 2015;11(9):2142-2157.

[9] Towers S, Brauer F, Castillo-Chavez C, Falconar AK, Mubayi A, Romero-Vivas CM. Estimate of the reproduction number of the 2015 Zika virus outbreak in Barranquilla, Colombia, and estimation of the relative role of sexual transmission. Epidemics. 2016 Dec 1; 17:50-5.

[10] Fine PE. Herd immunity: history, theory, practice. Epidemiologic reviews. 1993 Jan 1;15(2):265-302.

[11] Ferguson N, Cummings D, Fraser C, Cajka J, Cooley P, Burke D. Strategies for mitigating an influenza pandemic. Nature. 2006;442(7101):448-452.

[12] Farrington CP, Whitaker HJ. Estimation of effective reproduction numbers for infectious diseases using serological survey data. Biostatistics. 2003 Oct 1;4(4):621-32.

[13] Garnett GP. Role of herd immunity in determining the effect of vaccines against sexually transmitted disease. The Journal of infectious diseases. 2005 Feb 1;191: S97.

[14] Delamater PL, Street EJ, Leslie TF, Yang YT, Jacobsen KH. Complexity of the Basic Reproduction Number ([R. sub. 0]). Emerging Infectious Diseases. 2019 Jan 1;25(1):1-5.

[15] Chakrabarti S, Kaur U, Singh A, Chakrabarti S, Krishnatreya M, Agrawal B et al. Of Cross-immunity, Herd Immunity and Countryspecific Plans: Experiences from COVID-19 in India. Aging and disease. 2020;11(6):1339.

[16] Jamal A. Coronavirus: Localised herd immunity, young population behind dip in India's Covid count? [Internet]. Hindustan Times. 2021 $\begin{array}{llll}\text { [cited } & 8 & \text { January 2021]. Available from: }\end{array}$ https://www.hindustantimes.com/health/coronavirus-localised-herdimmunity-young-population-behind-dip-in-india-s-covid-count/story9SuZUttGdCkF6Lzi2pn1uL.html.

[17] Banaji M. Herd Immunity for COVID-19 - a Straightforward Explainer - The Wire Science [Internet]. The Wire Science. 2020 [cited 9 January 2021]. Available from: https://science.thewire.in/health/india-covid-19-epidemic-herdimmunity-threshold-lockdown-vaccine-mitigation/.

[18] Wise, J., 2020. Covid-19: New coronavirus variant is identified in UK. $B M J$, p.m 4857.

[19] Keeling MJ, Gilligan CA. Metapopulation dynamics of bubonic plague. Nature. 2000 Oct;407(6806):903-6.

[20] Fenner F, Henderson DA, Arita I, Jezek Z, Ladnyi ID. Smallpox and its eradication. Geneva: World Health Organization; 1988 Mar 2.

[21] Venkatasen M, Mathivanan SK, Jayagopal P, Mani P, Rajendran S, Subramaniam U, Ramalingam AC, Rajasekaran VA, Indirajithu A, Somanathan MS. Forecasting of the SARS-CoV-2 epidemic in India using SIR model, flatten curve and herd immunity. Journal of ambient intelligence and humanized computing. 2020 Nov 15:1-9.

[22] Shubhra CS, Upinder K, Anindita B, Upasana G, Tuhina B, Sarama S, Gaurav P, Suvarna P, Suddhachitta C, Amit M, Kumar AB. COVID19 in India: Are Biological and Environmental Factors Helping to Stem the Incidence and Severity?. Aging and disease. 2020 May 13;11(3):480-8.

[23] Beck HE, Zimmermann NE, McVicar TR, Vergopolan N, Berg A, Wood EF (2018). Present and future Köppen-Geiger climate classification maps at 1-km resolution. Sci Data, 5:180214.

[24] Wang J, Tang K, Feng K, Lv W (2020). High Temperature and High Humidity Reduce the Transmission of COVID-19. Available at SSRN.doi: 10.2139/ssrn.3551767.

[25] Sardar R, Satish D, Birla S, Gupta D. Comparative analyses of SARCoV2 genomes from different geographical locations and other coronavirus family genomes reveals unique features potentially consequential to host-virus interaction and pathogenesis.

[26] Mourya DT, Yadav PD, Ullas PT, Bhardwaj SD, Sahay RR, Chadha MS, Shete AM, Jadhav S, Gupta N, Gangakhedkar RR, Khasnobis P. Emerging/re-emerging viral diseases \& new viruses on the Indian horizon. Indian Journal of Medical Research. 2019 Apr 1;149(4):44.

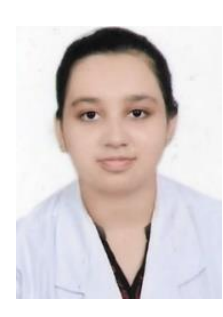

Sheema Fatima Khan is medical student of Shadan Institute of Medical Sciences, Research and Teaching center, Hyderabad, India.

She was also high school topper in International Indian School Jeddah in March 2019.

https://telanganatoday.com/nri-students-in-gulf-excel-

cbse-12th-results

https://saudigazette.com.sa/article/565448.

Her aim is to become a researcher in virology. 